\title{
Bioanalysis
}

\section{So you think your assay is robust?} "...scientists often claim that their assays are robust or rugged in a very casual way,
often without any experimental data to back up their claim." Keywords: International Conference on Harmonization $(\mathrm{ICH}) \bullet$ LC-MS $\bullet$ microsampling
- precision $\bullet$ proteins $\bullet$ robustness $\bullet$ ruggedness

In the world of regulated LC-MS bioanalysis, in which decisions are normally data driven and fact based, it is quite surprising that our scientists often claim that their assays are robust or rugged in a very casual way, often without any experimental data to back up their claim. Robust and rugged are often used interchangeably to simply mean a 'good' assay. Both authors of this editorial cut their regulatory teeth in Good Manufacturing Practice (GMP) analytical laboratories (Bristol-Myers Squibb and Wyeth-Ayerst), where robustness and ruggedness of analytical methodologies have specific meanings and are tested according to United States Pharmacopeia (USP) chapters [1] and International Conference of Harmonization (ICH) guidelines [2]. For the last several years, both of them have held senior positions in Good Laboratory Practice (GLP) bioanalytical departments at two major pharmaceutical companies.

In this editorial, the authors would like to share their thoughts on the topics of robustness and ruggedness in the hope that the bioanalytical community will get an appreciation of the significance of robustness and ruggedness testing and start thinking how these concepts could be implemented in LC-MS bioanalytical laboratories.

In the GMP definition, a robust assay is one that will remain 'unaffected by small but deliberate changes in test conditions' [2]. The purpose of the robustness test is to uncover critical parameters that can potentially compromise assay performance. During robustness testing, experimental parameters (e.g., injection volume, gradient shape, column lots, flow rate, mobile phase composition), are deliberately altered to see whether or not the method results are affected. Design of experiment methods (DOE) such as screening, full factorial and fractional factorial designs are often used to study the critical parameters as well as their inter-relationships [3]. Ruggedness on the other hand describes the reproducibility of the assay under variable but normal test conditions such as different instruments, reagent lots, assay temperature, analysts and laboratories (USP Chapter 1225). The term ruggedness is not used by the $\mathrm{ICH}$, but is addressed in ICH guideline Q2 (R1) under intermediate precision (within-laboratory variations) and reproducibility (betweenlaboratory variations) [2]. In GMP testing, an assay conducted in quality control laboratories across the world will rely on the original validation done during late development and the interlaboratory testing done during assay transfer. In these conditions, ruggedness is essential. The requirements for ruggedness are not the same in bioanalysis, in which each instance of the assay is redeveloped and validated after technology transfer.

Practically, understanding the robustness will help troubleshoot issues that surface during ruggedness testing. An assay whose performance is very sensitive to small changes of one or more critical parameters will be more susceptible to poor ruggedness if those critical parameters are not well controlled.

In current regulatory guidelines pertinent to bioanalytical assay validation and

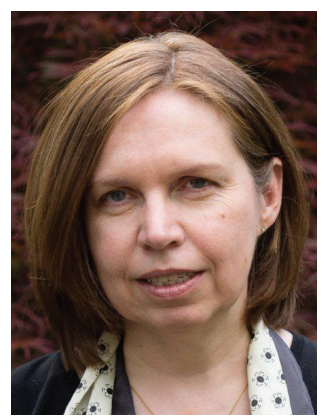

Anne-Françoise Aubry Author for correspondence Bristol Myers Squibb, Analytical \& Bioanalytical Development, PO Box 4000, Princeton, NJ 08540-4000, USA anne.aubry@bms.com

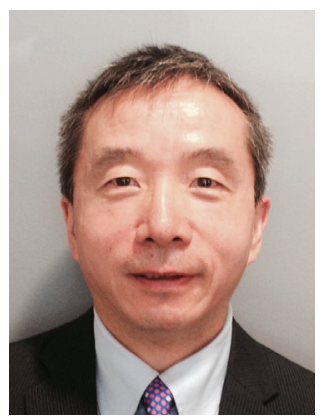

Naidong Weng Janssen Research \& Development, Pharmacokinetics, Dynamics \& Metabolism, 1400 McKean Road, Spring House, PA 19477, USA 
sample analysis, the term ruggedness is not mentioned, although one can interpret the partial validation requirement for the assay transfer to be the same as that described in the ICH guideline for reproducibility. Interday analysis, the use of different lots of matrix and incurred sample reanalysis (ISR), which are required by all bioanalytical guidelines, are tests designed to provide some insights on assay ruggedness (Table 1). Assay robustness is mentioned only in the Brazilian Agência Nacional de Vigilância Sanitária (ANVISA) guideline, which specifically requests "studying the main parameters susceptibility to variations prior to the validation." It must be noted here that robustness testing is routinely applied during the development of ligand binding assay (LBA) and others assays; often using a DOE approach and that robustness was included in the 2003 white paper on assay validation of LBAs [4].

\section{"Quantitative LC-MS assays used in regulated bioanalysis for small molecules are generally very rugged."}

Quantitative LC-MS assays used in regulated bioanalysis for small molecules are generally very rugged. The use of an internal standard (stable isotope labeled analyte in particular) and the extraordinary specificity of mass spectrometric detection render bioanalytical assays very tolerant to small changes in experimental conditions. There are exceptions, many of which have been well described in the published literature, most recently by Unger $e t a l$. [9], with examples of validated assays failing in routine sample analysis because a critical aspect had been overlooked. Good method development includes aspects of robustness testing and conscientious analysts complete method development with a good understanding of critical parameters. However, method development does not equal robustness testing, which is normally done after the method has been finalized and should be based on statistical comparison of results. In our opinion, assays with complex sample preparation and less-than-ideal internal standards, such as those used to support new scaffolds (e.g., biologics or antibody-drug conjugate assays requiring immunocapture and digestion), DBS or microsampling would benefit from robustness testing. In a recent example for a small molecule drug, a DOE was conducted to optimize the extraction procedure for a drug and its metabolite that had very different physicochemical properties when sensitivity was critical [10]. This systematic approach is powerful in identifying and controlling critical parameters.

Ruggedness is easier to establish and can often be claimed at posteriori by reviewing assay performance in sample analysis over a long period of time [11]. Clearly, it is useful to be aware of ruggedness issues before the assay goes into routine sample analysis. Even though not clearly stated in regulatory guidelines, ruggedness can be inferred from the interday precision. It has been our observation, however, that, when evaluating precision and accuracy, the only sources of variability that are systematically included in validation are the day of analysis and the matrix lots. For expediency, many validations are conducted with one preparation of QC samples, one single batch of mobile phase or reagents, one instrument, one analyst, etc. Statistically, it would be much better and not really more time consuming, to include more sources of variability upfront within the validation by systematically preparing new batches of mobile phases, stock solutions. QCs for at least some of the validation runs and using multiple instruments

Table 1. How ruggedness and robutness are addressed in current bioanalytical method validation guidances and guidelines.

\begin{tabular}{|c|c|c|}
\hline Regulatory body & Robustness & Ruggedness \\
\hline $\begin{array}{l}\text { US FDA, European } \\
\text { Medicines Agency } \\
\text { (EMA), Japanese NIHS }\end{array}$ & Not mentioned & $\begin{array}{l}\text { Intermediate precision (within-laboratory } \\
\text { variations): ISR, day of analysis and matrix } \\
\text { lots } \\
\text { Reproducibility (between-laboratory } \\
\text { variations): partial validation for } \\
\text { transferred assay }\end{array}$ \\
\hline ANVISA & $\begin{array}{l}\text { Studying the main parameters } \\
\text { susceptibility to variations } \\
\text { prior to the validation }\end{array}$ & $\begin{array}{l}\text { Intermediate precision (within-laboratory } \\
\text { variations): ISR, day of analysis and matrix } \\
\text { lots } \\
\text { Reproducibility (between-laboratory } \\
\text { variations): partial validation for } \\
\text { transferred assay }\end{array}$ \\
\hline
\end{tabular}


and analysts whenever possible. If this is not a practical approach for the very first validation occurrence due to time and resource constraints or limited supply of reference material, this should be considered in subsequent validations or when the assay is transferred to a contract research organization.

While LC-MS bioanalytical assays are typically fairly rugged, and are validated in each laboratory where the assay is used, one should always be aware of the potential pitfalls of a given assay. It may be beneficial to implement a practical strategy of testing assay boundaries during method development and validation. Our recommendation is not to implement an extensive robustness testing for all methods but to consider it, on a case-by-case, for the more complex assays. Regarding ruggedness, the practice of conducting the validation using a single batch of mobile phase and QCs, and a single column and instrument leads to low percent $\mathrm{CV}$ that gives a false sense of security

\section{References}

1 USP 29, chapter <1225> Validation of Compendial Methods. https://hmc.usp.org/sites/default/files/documents/HMC/ GCs-Pdfs/c1225.pdf

2 International Conference on Harmonization (ICH) of Technical Requirements for the Registration of Pharmaceuticals for Human use, Validation of Analytical Procedures: Methodology. ICH Q2B, Geneva, Switzerland (1996).

www.fda.gov/downloads/drugs/

guidancecomplianceregulatoryinformation/guidances/ ucm073384.pdf

3 Cowan KJ, Erickson R, Sue B et al. Utilizing design of experiments to characterize assay robustness. Bioanalysis 4(17), 2127-2139 (2012).

4 DeSilva B, Smith W, Weiner R et al. Recommendations for the bioanalytical method validation of ligand-binding assays to support pharmacokinetic assessments of macromolecules. Pharm. Res. 20(11), 1885-1900 (2003).

5 Guidance for Industry Bioanalytical Method Validation, FDA May (2001).

www.fda.gov/downloads/Drugs/

Guidancecomplianceregulatoryinformation/Guidances/ ucm070107.pdf that the assay is performing well. Introducing more sources of variability in the validation is a way to get some assurance that the assay is sufficiently rugged to be used on a study. The ultimate test for ruggedness is good reproducibility and low failure rate during sample analysis. Finally, we all have to be careful about our use of these terms and stop making claims on assay robustness if we have not tested the assay boundaries during development and/or validation.

\section{Financial \& competing interests disclosure}

The authors of this article are current employees of BristolMyers Squibb Company (BMS) or Janssen R\&D. The authors have no other relevant affiliations or financial involvement with any organization or entity with a financial interest in or financial conflict with the subject matter or materials discussed in the manuscript apart from those disclosed.

No writing assistance was utilized in the production of this manuscript.

6 European Medicine Agency Guideline on Bioanalytical Method Validation, February (2012).

www.ema.europa.eu/docs/en_GB/document_library/ Scientific_guideline/2011/08/WC500109686.pdf

7 Guideline on Bioanalytical Method Validation in Pharmaceutical Development, Japanese NIHS. www.nihs.go.jp/drug/BMV/250913_BMV-GL_E.pdf

8 ANVISA's Bioanalytical Guidance. RDC 27/2012 (RESOLUÇÃO RDC N.․ 27, DE 17 DE MAIO DE 2012). http://portal.anvisa.gov.br/wps/wcm/connect/564310004b6 0537e891f9baf8fded4db/RDC+27+12+-Valida\%C3\%A7\% $\mathrm{C} 3 \% \mathrm{~A} 3 \mathrm{o}+\mathrm{de}+\mathrm{M} \% \mathrm{C} 3 \% \mathrm{~A} 9$ todos+Bioanal\%C3\%ADticos. pdf?MOD=AJPERES

9 Unger $\mathrm{S}$, Horvath $\mathrm{T}$, Tan $\mathrm{M}$ et al. Making methods rugged for regulated bioanalysis. Bioanalysis 7(7), 833-852 (2014).

10 Dawes ML, Bergum JS, Schuster AE, Aubry AF. Application of a design of experiment approach in the development of a sensitive bioanalytical assay in human plasma. J. Pharm. Biomed. Anal. 70, 401-407 (2012).

11 White S, Dunn J, Summerfield S. The quest for assay robustness across the life cycle of a bioanalytical method. Bioanalysis 7(7), 815-824 (2014). 